\title{
Managerial attitude to the implementation of quality management systems in Lithuanian support treatment and nursing hospitals Ilona Buciuniene $e^{* 1,2}$, Sonata Malciankina ${ }^{\dagger 3}$, Zigmas Lydeka ${ }^{\dagger 4}$ and Ruta Kazlauskaite ${ }^{\dagger 1}$
}

Address: ${ }^{1}$ Department of Intellectual Capital and Business Competence, ISM University of Management and Economics, Ozeskienes Street 18, LT44254 Kaunas, Lithuania, ${ }^{2}$ Department of Social Medicine, Kaunas University of Medicine, Kaunas, Lithuania, ${ }^{3}$ Kaunas Terminal Care Hospital, Kaunas, Lithuania and ${ }^{4}$ Vytautas Magnus University, Kaunas, Lithuania

Email: Ilona Buciuniene* - ilona.buciuniene@ism.lt; Sonata Malciankina - smalcankina@yahoo.com; Zigmas Lydeka - zigmas.lydeka@ism.lt; Ruta Kazlauskaite - ruta.kazlauskaite@ism.lt

* Corresponding author †Equal contributors

Published: 20 September 2006

BMC Health Services Research 2006, 6:120 doi:10.1 186/1472-6963-6-120
Received: 24 November 2005

Accepted: 20 September 2006

This article is available from: http://www.biomedcentral.com/1472-6963/6/120

(c) 2006 Buciuniene et al; licensee BioMed Central Ltd.

This is an Open Access article distributed under the terms of the Creative Commons Attribution License (http://creativecommons.org/licenses/by/2.0), which permits unrestricted use, distribution, and reproduction in any medium, provided the original work is properly cited.

\begin{abstract}
Background: The regulations of the Quality Management System (QMS) implementation in health care organizations were approved by the Lithuanian Ministry of Health in 1998. Following the above regulations, general managers of health care organizations had to initiate the QMS implementation in hospitals. As no research on the QMS implementation has been carried out in Lithuanian support treatment and nursing hospitals since, the objective of this study is to assess its current stage from a managerial perspective.
\end{abstract}

Methods: A questionnaire survey of general managers of Lithuanian support treatment and nursing hospitals was carried out in the period of January through March 2005. Majority of the items included in the questionnaire were measured on a seven-point Likert scale. During the survey, a total of 72 questionnaires was distributed, out of which 58 filled-in ones were returned (response rate 80.6 per cent; standard sampling error 0.029 at 95 per cent level of confidence).

Results: Quality Management Systems were found operating in 39.7 per cent of support treatment and nursing hospitals and currently under implementation in 46.6 per cent of hospitals (I3.7\% still do not have it). The mean of the respondents' perceived QMS significance is 5.8 (on a seven-point scale). The most critical issues related to the QMS implementation include procedure development (5.5), lack of financial resources (5.4) and information (5.I), and development of work guidelines (4.6), while improved responsibility and power sharing (5.2), better service quality (5.I) and higher patient satisfaction (5.I) were perceived by the respondents as the key QMS benefits. The level of satisfaction with the QMS among the management of the surveyed hospitals is mediocre (3.6). However it was found to be higher among respondents who were more competent in quality management, were familiar with ISO 9000 standards, and had higher numbers of employees trained in quality management.

Conclusion: QMSs are perceived to be successfully running in one third of the Lithuanian support treatment and nursing hospitals. Its current implementation stage is dependent on the hospital size - the bigger the hospital the more success it meets in the QMS implementation. As to critical Quality Management (QM) issues, hospitals tend to encounter such major problems as lack of financial resources, information and training, as well as difficulties in procedure development. On the other hand, the key factors that assist to the success of the QMS implementation comprise managerial awareness of the QMS significance and the existence of employee training systems and audit groups in hospitals. 


\section{Background}

In the 1990s, the greater part of the world's health care policy makers realised the great significance of quality in health care organizations, which led to the initiation of respective actions. For instance, Swedish hospitals started quality-related initiatives back in 1992 [1]. France started its health care reform in 1996, which among other issues was aimed at quality assurance and hospital accreditation [2]. Considerable attention has recently been given to the effective management and delivery of health care services in Irish health care organizations [3]. The 1997 UK government White Paper clearly stated that sustaining of the NHS was reliant upon a "new drive for quality" [4]. In the Netherlands, a law passed in 1996 provided national quality requirements for health care organizations [5].

The Quality Management System (QMS) is a coordinated aggregate of interrelated and interactive activities that determine quality policy and objectives as well as provides health care organisations with guidance and rules in their goal attainment [6]. The implementation of quality management systems enables health care organizations to define and manage processes that ensure delivery of services that meet customer needs and expectations. Besides it installs trust in both organizations and consumers in respect to service quality and conformity to respective standards.

Lithuanian health care organizations are obliged to implement quality management systems as to the law passed by the Lithuanian Ministry of Health in October 1998 [7]. The above law provides the procedure of the QMS implementation in health care organizations and commits their management to its execution: the general manager of a hospital has to appoint the local audit group manager, who in turn is responsible for the formation of the audit group. The latter then controls the QMS operation, prepares all the necessary documentation, etc. However the Ministry of Health did not provide health care organizations the needed support in QMS implementation and did not ensure a systemic coordination of the quality improvement process. It was only in 2000, when in collaboration with the Danish Health Ministry, guidelines for QMS implementation were developed and published [8].

The QMS implementation encountered a number of barriers in Lithuania, such as insufficient methodological assistance from respective state institutions, lack of quality management knowledge, insufficient motivation of health care managers and professionals to participate in health care quality improvement activities, and quality standards [8], which conditioned slow national development of the QMS in health care organizations.
In the Soviet period (1941-1990), Lithuania did not have any support treatment and nursing hospitals. The first ones were established in the country only in 1990, after the initiation of the national health care reform. As to Lithuanian medical norm MN 80:2000, support treatment and nursing hospitals are health care organizations that provide first level in-patient support treatment and nursing services to disabled persons and people suffering from chronic ailments [9]. The above norm defines support treatment as in-patient medical support provided to patients for whom diagnosis has been made and who do not require specialized treatment [9]. Nursing is defined as nursing activities that assist in sustaining a patient's vital body functions [9]. Support treatment and nursing hospitals provide long-term treatment, i.e. patients are hospitalised for up to 120 and more days, which necessitates assuring qualitative care and meeting patients' needs. Lithuanian support treatment and nursing hospitals have to follow the above-mentioned general regulations of the QMS implementation.

\section{Research objective}

As no research on the QMS implementation has been carried out in Lithuanian support treatment and nursing hospitals before, the objective of this study is to assess its current QMS implementation stage from a managerial perspective.

\section{Research goals}

1. to examine managerial perceptions of the current QMS implementation progress in Lithuanian support treatment and nursing hospitals;

2. to identify problems arising in the QMS implementation in Lithuanian support treatment and nursing hospitals;

3. to assess the level of managerial satisfaction with the currently operating quality management systems;

4. to compare and contrast the QMS implementation in different size hospitals.

\section{Methods \\ Sample}

A population survey of Lithuanian support treatment and nursing hospitals was carried out. According to the data of the Lithuanian Health Information Centre, there were 72 hospitals of the kind in Lithuania in 2004 [10]. The study group consisted of the management of support treatment and nursing hospitals.

A quantitative research method, i.e. a questionnaire survey, was chosen to attain the research goals. The survey was a cross sectional, one time assessment of the manage- 
rial attitude to the QMS implementation in support treatment and nursing hospitals. The survey was carried out in the period of January through March 2005. During the survey, a total of 72 questionnaires was distributed, out of which 58 filled-in ones were returned (response rate 80.6 per cent; standard sampling error 0.029 at 95 per cent level of confidence) [11].

\section{Questionnaire development}

Given the fact that the regulations of the QMS implementation in Lithuanian health care organizations were developed under ISO standards [6], the questionnaire was designed following the above standards and prior research on QMS in health care organizations [12-18].

The questionnaire items fell under the following four major categories: 1) general questions, 2) questions on the current QMS implementation stage, 3) questions on problems that may have arisen in the QMS implementation process, and 4) questions on QMS benefits and the level of managerial satisfaction with the operating QMS. The respondents were asked to rank their agreement/disagreement with the provided statements on a seven-point Likert scale (see Additional file 1).

\section{Questionnaire reliability}

Cronbach's Alpha was used to assess the questionnaire reliability (only for items measured on a seven-point Likert scale). An alpha value of 0.80 or higher was considered as acceptable reliability [19]. The questionnaire reliability coefficient was 0.86 . The questionnaire was pilot tested with ten managers of randomly selected hospitals.

\section{Data collection process}

Questionnaire packages contained a cover letter with an explanation of the survey purpose and guarantee of response confidentiality, a questionnaire, and a pre-paid return envelope. Questionnaires were mailed to general managers of 72 support treatment and nursing hospitals. After a week, all the above managers were telephoned and reminded of the survey. 20 filled-in questionnaires were received after the first call. In another two weeks, the remaining 52 hospitals were given a second call. All in all, 58 filled-in questionnaires were returned.

\section{Data analysis}

The survey data was processed using the SPSS statistical package (version 11). The statistical data reliability was checked according to $\chi^{2}$ criteria, degrees of freedom number (df), and statistical significance. The relationship between two independent variables was assessed by calculating Spearman's rank correlation coefficients, taking into consideration the value of the correlation ratio and its statistical significance (reliability notation: $\mathrm{p}<0.05$ means statistically significant, $\mathrm{p}<0.01$ highly significant).
Explanatory factor analysis was used to reduce the number of QMS-related benefits and problems.

For analysis purposes, all support treatment and nursing hospitals under the survey were subdivided into three major groups in respect to the number of employees:

1. small, with the employee number under 50;

2. medium, with employee number ranging between 50 and 100;

3. large, with employee number over 100.

Respectively 46.6 per cent of the support treatment and nursing hospitals fell under the first group, 29.3 were categorized as medium sized, and 24.1 small-sized (see Table 1 ). Based on the number of years spent working for a health care organization, respondents distributed as follows: 29 (50\%) have worked for up to 5 years; $23(40 \%)$ 6 to 10 years; and $6(10 \%)$ over 10 years. The above rather low figures can be accounted for by the fact that the first support treatment and nursing hospitals were established only in 1990.

\section{Results \\ The current QMS implementation stage: managerial perceptions}

The analysis of managerial attitude towards the QMS implementation in Lithuanian support treatment and nursing hospitals showed that the QMS operates in 39.7 per cent of organizations and is currently under development in 46.6 per cent of hospitals (13.7 per cent still do not have it). The QMS implementation stage was found to vary among different size hospitals: it is under development in 51.9 per cent of small, 58.8 per cent of medium, and 21.4 per cent of large hospitals (see Table 1 ).

Quality audit groups have been set-up in 70.7 per cent of hospitals, while 29.3 per cent of organizations still do not have them. It is noteworthy that all large-scale hospitals have audit groups, while the same figure among small size institutions is just a bit over 50 per cent.

Employee training systems currently operate in 56.9 per cent of hospitals. QM-related training systems have been developed in a statistically significant greater part of large hospitals $(85.7 \%)$ in comparison to medium $(58.8 \%)$ and small-size (40.7\%) hospitals.

\section{Perceived QMS significance}

The mean of the perceived QMS significance is 5.76 on a seven-point scale (see Table 2 ). In respect to the hospital size, there are no statistically significant differences in the QMS significance ranking among the three hospital 


\begin{tabular}{|c|c|c|c|c|c|c|c|c|c|}
\hline \multirow[t]{3}{*}{ Criterion } & \multicolumn{6}{|c|}{ Hospital size (number of employees) } & \multicolumn{2}{|c|}{ Total } & \\
\hline & \multicolumn{2}{|c|}{ Small (Under 50) } & \multicolumn{2}{|c|}{ Medium (50-100) } & \multicolumn{2}{|c|}{ Large (over 100) } & \multirow[b]{2}{*}{$\mathrm{n}$} & \multirow[b]{2}{*}{$\%$} & \\
\hline & $\mathrm{n}$ & $\%$ & $\mathrm{n}$ & $\%$ & $\mathrm{n}$ & $\%$ & & & \\
\hline Current QMS implementation stage & & & & & & & & & $\begin{array}{c}\chi^{2}=15.69 ; \mathrm{df}=4 ; \mathrm{p}=0.003 \\
* p<0.05 \text { as compared to large-size hospitals. } \\
* * \mathrm{p}<0.05 \text { in comparison to other size hospitals }\end{array}$ \\
\hline QMS under implementation & 14 & 51.9 & 10 & 58.8 & 3 & $21.4^{*}$ & 27 & 46.6 & \\
\hline QMS implemented & 6 & 22.2 & 6 & 35.3 & 11 & $78.6^{* *}$ & 23 & 39.7 & \\
\hline QMS implementation not started & 7 & 25.9 & 1 & 5.9 & 0 & 0.0 & 8 & 13.8 & \\
\hline Total & 27 & 100 & 17 & 100 & 14 & 100 & 58 & 100 & \\
\hline Quality audit group formation & & & & & & & & & $\begin{array}{l}\qquad \chi^{2}=10.7 ; \mathrm{df}=2 ; \mathrm{p}=0.005 \\
*_{p}<0.05 \text { in comparison to other size hospitals having audit groups. }\end{array}$ \\
\hline Group formed & 14 & $51.9 *$ & 13 & 76.5 & 14 & 100 & 41 & 70.7 & \\
\hline Group not formed & 13 & 48.1 & 4 & 23.5 & 0 & 0 & 17 & 29.3 & \\
\hline Total & 27 & 100 & 17 & 100 & 14 & 100 & 58 & 100 & \\
\hline Training in QMS & & & & & & & & & $\chi^{2}=7.64 ; d f=2 ; p=0.02$ \\
\hline System developed & $\mathrm{II}$ & 40.7 & 10 & 58.8 & 12 & 85.7 & 33 & 56.9 & \\
\hline System absent & 16 & 59.3 & 7 & 41.2 & 2 & 14.3 & 25 & 43.1 & \\
\hline Total & 27 & 100 & 17 & 100 & 14 & 100 & 58 & 100 & \\
\hline
\end{tabular}


Table 2: Perceived QMS significance and satisfaction with QMS in Lithuanian support treatment and nursing hospitals

\begin{tabular}{|c|c|c|c|c|c|}
\hline \multirow[t]{2}{*}{ Criterion } & \multicolumn{2}{|c|}{ QMS significance } & \multicolumn{2}{|c|}{ Satisfaction with QMS } & \\
\hline & Means & Standard deviation (SD) & Means & Standard deviation (SD) & \\
\hline Overall & 5.76 & 1.14 & 3.6 & 1.6 & \\
\hline $\begin{array}{l}\text { Hospitals with quality } \\
\text { management training systems }\end{array}$ & $6.09 *$ & 1.07 & $4.3^{*}$ & 1.1 & $\begin{array}{c}* p<0.05 \text {, in comparison to } \\
\text { hospitals that do not have training } \\
\text { systems }\end{array}$ \\
\hline $\begin{array}{l}\text { Hospitals without quality } \\
\text { management training systems }\end{array}$ & 5.23 & 1.11 & 2.6 & 1.6 & \\
\hline $\begin{array}{l}\text { Hospitals with }<50 \\
\text { employees }\end{array}$ & 5.78 & 1.01 & 3.0 & 1.8 & $\begin{array}{c}* \mathrm{p}<0.05 \text {, in comparison to } \\
\text { other size hospitals }\end{array}$ \\
\hline $\begin{array}{l}\text { Hospitals with } 50 \text { to } 100 \\
\text { employees }\end{array}$ & 5.47 & 1.23 & 3.8 & 1.1 & \\
\hline $\begin{array}{l}\text { Hospitals with }>100 \\
\text { employees }\end{array}$ & 6.07 & 1.27 & $4.5^{*}$ & 1.2 & \\
\hline
\end{tabular}

groups under this study. However, the ranking of the perceived QMS significance differs between hospitals with QM training systems $($ mean $=6.09)$ and hospitals that do not have such systems $(5.23)(\mathrm{p}<0.05)$.

Depending on the existence/absence of employee training systems on quality management, research brought out a statistically significant difference as regards the managerial assessment of employee knowledge, i.e. managers of hospitals that have training systems rank their employee knowledge higher than those that do not have them (see Figure 1).

\section{Satisfaction with QMS}

The overall managerial satisfaction with the QMS is barely moderate $($ mean $=3.6$ on a 7 point scale) (see Table 2 ).

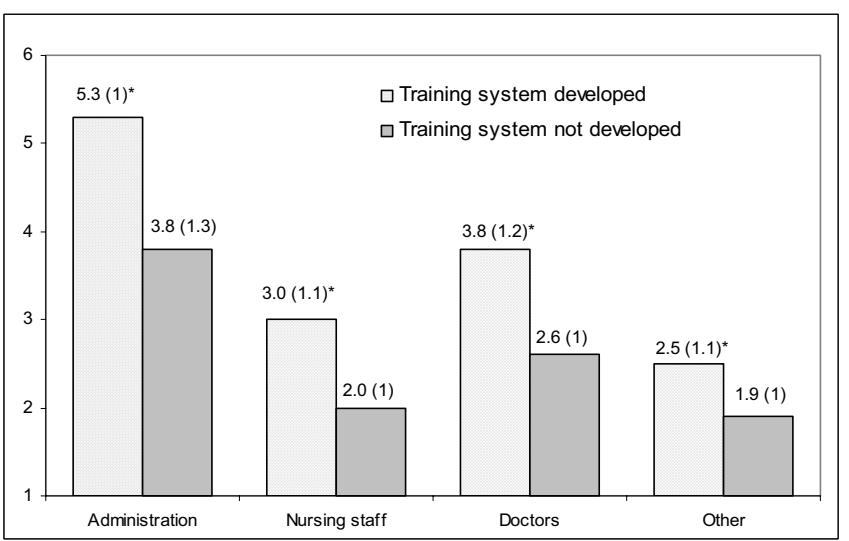

Figure I

Mean score of perceived employee quality management competence in respect to the existence of respective training systems (standard deviation).
Research findings show some statistically significant variances in satisfaction rating among different size hospitals: managers of large hospitals tend to be more satisfied with the QMS (4.5) than their counterparts in medium (3.8) and small (3.0) hospitals. Besides research results revealed statistically significant higher levels of managerial satisfaction with QMS in hospitals that have developed QM training systems (6.09) in contrast to those that have not (5.76).

Managerial satisfaction with the QMS was found to bear a high degree correlation with QM knowledge (Spearman's correlation ratio $=0.754, \mathrm{p}<0.01)$ and staff training in QM $(0.708, \mathrm{p}<0.01)$ (see Table 3 ). Moderate degrees of correlation were found between the managerial satisfaction with the QMS and knowledge of ISO 9000 standards (0.623, p < 0.01), doctors' QM competence $(0.617, \mathrm{p}<$ $0.01)$, administration's QM competence $(0.548, \mathrm{p}<$ $0.01)$, and nursing staff QM competence $(0.540, \mathrm{p}<$ $0.01)$.

QMS implementation problems: managerial perceptions Major problems that hospitals encountered in the QMS implementation tend to be as follows: procedure development (mean $=5.45)$, lack of financial resources (5.38), lack of information (5.06), and development of work instructions (4.73) (see Table 4). Some variances in the rating of the critical QMS implementation issues among different size hospitals were detected, but they are not statistically significant.

The results of the factor analysis of the QMS implementation problems indicate that there are four rotated factors, which explained a total variance of 73.26 per cent (KMO $\left.\mathrm{MSA}=0.557, \chi^{2}=252.300, \mathrm{df}=55, \mathrm{p}=0.000\right)$. These are as follows: QM competence and organizational resources 
Table 3: Relationship between satisfaction with QMS and criterion affecting it

\begin{tabular}{llc}
\hline Criterion & Satisfaction with QMS (Spearman's ratio) \\
\hline $\begin{array}{l}\text { Respondent's knowledge of quality management } \\
\text { Respondent's knowledge of ISO } 9000 \text { standards }\end{array}$ & $.754^{* *}$ \\
$\begin{array}{l}\text { Proportion of hospital staff to have attended training in quality management } \\
\text { Competence in quality management among other hospital staff (as perceived by }\end{array}$ & Administration & $.623^{* *}$ \\
the respondents) & Nursing staff & $.708^{* *}$ \\
& Doctors & $.548^{* *}$ \\
& Others & $.540^{* *}$ \\
$.617^{* *}$ & $.383^{* *}$
\end{tabular}

** $\mathrm{p}<0.01$

(staff training, procedure development, development of work instructions, lack of information, and lack of financial resources), QM policy (quality policy definition and quality goal setting), QM audit group activities (appointment of local audit group manager, audit group formation, and use of diagnostic and treatment methods), and staff resistance to the QMS implementation (see Table 5).

\section{Perceived QMS organizational benefits}

Out of the 13 proposed QMS organizational benefits, hospital managers perceived the following ones as of the highest relevance to their hospitals: improvement of responsibility and power sharing (mean $=5.2$ ), better service quality (5.1), higher patient satisfaction (5.1), and a stronger sense of security among patients (4.9) (see Figure 2).

Research findings showed that the relationships between the perceived QMS significance and 11 organizational benefits are statistically significant; the above relationships, however, are low to moderate (see Table 6). The highest of those were found between the perceived QMS significance and higher patient satisfaction (Spearman's ratio $=0.577, \mathrm{p}<0.01)$, more effective communication (0.477, p < 0.01), safer work environment $(0.461, \mathrm{p}<$ $0.01)$, and improved work organization $(0.402, \mathrm{p}<0.01)$.

The results of the factor analysis of the perceived QMS organizational benefits show that there are three rotated factors, which explained a total variance of 63.64 per cent $\left(\mathrm{KMO} M S A=0.824, \chi^{2}=307.555, \mathrm{df}=78, \mathrm{p}=0.000\right)$. These are as follows: improved work quality and safety (a stronger sense of security among patients, a lower number of undesirable incidents, a lower number of mistakes, improved work organization, and safer work environment), improved service quality and patient/employee satisfaction (improved service quality, higher patient satisfaction, more effective communication, higher employee motivation, improved responsibility and authority sharing), and improved organizational performance (improved financial situation, better employee relationship, and increased patient number) (see Table 7).

Table 4: QMS implementation problems in Lithuanian support treatment and nursing hospitals

\begin{tabular}{|c|c|c|c|c|c|c|c|c|c|c|c|}
\hline \multirow[t]{3}{*}{ QMS implementation problem } & \multicolumn{6}{|c|}{ Hospital size (number of employees) } & \multicolumn{5}{|c|}{ General } \\
\hline & \multicolumn{2}{|c|}{ Small (under 50) } & \multicolumn{2}{|c|}{ Medium (50-100) } & \multicolumn{2}{|c|}{ Large (over 100) } & \multirow[b]{2}{*}{ Mean } & \multirow[b]{2}{*}{ SD } & \multirow[b]{2}{*}{$\mathbf{X}^{2}$} & \multirow[b]{2}{*}{ df } & \multirow[b]{2}{*}{$\mathbf{p}$} \\
\hline & Mean & SD & Mean & SD & Mean & SD & & & & & \\
\hline Quality policy definition & 2.55 & 1.57 & 2.47 & 1.12 & 2.86 & 1.56 & 2.60 & 1.42 & 0.60 & 2 & .74 \\
\hline Quality goal setting & 2.86 & 1.52 & 2.59 & 1.12 & 2.64 & 1.78 & 2.72 & 1.46 & 0.72 & 2 & .70 \\
\hline Appointment of local audit group manager & 3.14 & 1.61 & 3.29 & 1.69 & 2.71 & 1.59 & 3.08 & 1.62 & 1.17 & 2 & .56 \\
\hline Audit group formation & 4.68 & 2.15 & 4.18 & 1.91 & 3.07 & 1.64 & 4.09 & 2.02 & 5.77 & 2 & .06 \\
\hline Personnel training & 4.18 & 1.18 & 4.47 & 1.42 & 4.57 & 1.50 & 4.38 & 1.33 & 1.09 & 2 & .58 \\
\hline Procedure development & 5.41 & 1.44 & 5.65 & 1.37 & 5.29 & 1.44 & 5.45 & 1.39 & 0.55 & 2 & .76 \\
\hline Development of job instructions & 4.73 & 1.45 & 4.65 & 1.00 & 4.50 & 1.87 & 4.64 & 1.43 & 0.06 & 2 & .97 \\
\hline Use of diagnostic and treatment methods & 3.91 & 1.41 & 3.82 & 1.55 & 4.29 & 1.54 & 3.98 & 1.47 & 0.55 & 2 & .76 \\
\hline Staff resistance to QMS implementation & 3.09 & 1.48 & 2.88 & 1.05 & 2.64 & 1.50 & 2.91 & 1.35 & 1.26 & 2 & .53 \\
\hline Information deficiency & 4.68 & 1.36 & $5.65^{*}$ & 1.41 & 4.93 & 1.49 & 5.06 & 1.45 & 6.46 & 2 & .04 \\
\hline Lack of financial resources & 5.32 & 1.81 & 5.71 & 1.31 & 5.07 & 1.86 & 5.38 & 1.67 & 0.66 & 2 & .72 \\
\hline
\end{tabular}

$*_{p}<0.05$, statistically significant difference in comparison to hospitals with employee number under 50 
Table 5: Factor analysis of the perceived QMS benefits

\begin{tabular}{|c|c|c|c|}
\hline Factor & Variable & Loading & Total variance explained \\
\hline \multirow[t]{5}{*}{ Factor I Improved work quality and safety } & Stronger sense of security among patients & .727 & $44.45 \%$ \\
\hline & Lower number of undesirable incidents & .782 & \\
\hline & Lower number of mistakes & .673 & \\
\hline & Improved work organization & .548 & \\
\hline & Safer work environment & .760 & \\
\hline \multirow{5}{*}{$\begin{array}{l}\text { Factor II Improved service quality and patient/ } \\
\text { employee satisfaction }\end{array}$} & Improved service quality & .736 & $10.43 \%$ \\
\hline & Higher patient satisfaction & .630 & \\
\hline & More effective communication & .611 & \\
\hline & Higher employee motivation & .695 & \\
\hline & Improved responsibility and authority sharing & .498 & \\
\hline \multirow[t]{3}{*}{ Factor III Improved organizational performance } & Improved financial situation & .466 & $8.76 \%$ \\
\hline & Better employee relationship & .707 & \\
\hline & Increased patient number & .441 & \\
\hline
\end{tabular}

\section{Discussion}

Research findings showed that given the managerial perceptions the QMS has so far been implemented in one third of Lithuanian support treatment and nursing hospitals. Prior research on the QMS implementation in another three EU countries revealed less prominent results: the QMS was implemented in 4 per cent of Dutch hospitals, 0 per cent in Hungary, and 3 per cent in Finland [5]. However this comparison does not allow making any far-reaching conclusions, as the two studies used different QMS implementation assessment measures. The Lithuanian study was based on the managerial perceptions of the QMS implementation, and the three-country research focused on a number of QM activities based on which the QMS implementation stage was determined. Besides it was carried out in general hospitals, while the Lithuanian case is exclusively built on the support treatment and nursing hospitals.

The biggest contribution of this research is that it shows a relationship between the hospital size and QMS imple-

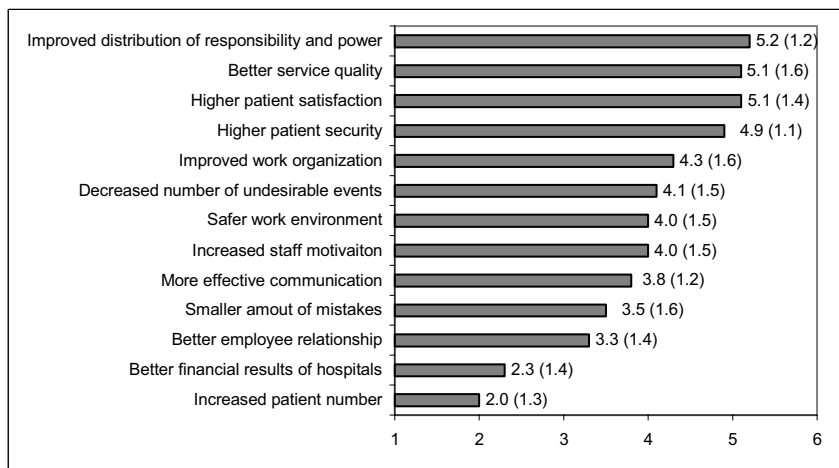

Figure 2

Mean score of QMS perceived benefit ranking (standard deviation). mentation. This issue has not been studied earlier, yet it is one of the most crucial factors in the QMS implementation in hospitals. Though, on the one hand, the scope of QMS-related work is typically narrower in small organizations in comparison to large ones, on the other hand, smaller organizations usually suffer a bigger shortage of resources, especially human resources. Such a situation, in turn, conditions problems in the establishment of audit groups, which are one of the key success factors in the QMS implementation. Larger institutions have fewer problems, and their management experience higher levels of satisfaction with the QMS. Small hospitals are therefore recommended to cooperate in the establishment of audit groups, i.e. forming one audit group which would comprise representatives delegated by a number of hospitals. This would assist in solving the problem of human resource scarcity and facilitate procedure development. It is also recommended for smaller hospitals to share experience in staff involvement in QM processes, and cooperate in organising staff training in QM.

From the managerial perspective, the most critical issues encountered in the QMS implementation in Lithuanian support treatment and nursing institutions were as follows: procedure development, personnel training, and lack financial resources and information. The above research findings are congruent to prior study results, which also point out such QMS-related problems as lack of financial resources $[13,14]$ and HRM-related critical issues [14].

Taking into account the fact that QMS implementation was initiated in Lithuanian hospitals at the end of 1998 and a relatively small size of support treatment and nursing hospitals, it can be stated that the QMS implementation in the above institutions is rather lengthy (7 years) in comparison to business organizations, where QMS implementation averages 1.67 years [20]. An assumption thus 
Table 6: Spearman's correlation ratio between perceived QMS organizational benefits and QMS significance

\begin{tabular}{lc}
\hline QMS benefit & QMS significance (Spearman's ratio) \\
\hline Improved financial situation & $.386^{* *}$ \\
Higher service quality & $.349^{*}$ \\
Higher employee motivation & $.379^{* *}$ \\
Stronger sense of security among patients & $.332^{*}$ \\
Lower number of mistakes & $.32 I^{*}$ \\
Better employee relationship & $.377^{* *}$ \\
Lower number of undesirable incidents & $.389^{* *}$ \\
Improved work organization & $.402^{* *}$ \\
Higher patient satisfaction & $.577^{* *}$ \\
More effective communication & $.477^{* *}$ \\
Safer work environment & $.46 I^{* *}$ \\
Increased patient number & .2 \\
Improved responsibility and authority sharing & .26 \\
\hline
\end{tabular}

$* \mathrm{p}<0.05 ; * * \mathrm{p}<0.01$

can be made that such a slow QMS implementation process is related to a lack of comprehensive standards authorised by the Ministry of Health [12]. The paper, however, did not look into the key factors that might have conditioned this rather lengthy time scope. However, the above situation may possibly be accounted for by the inefficiency of the national health care policy, insufficient commitment to QM, etc. Whatever the causes, the lengthy QMS implementation constitutes a serious problem and calls for an adequate consideration on the side of health care politicians.

Research into the implementation of quality management systems in Lithuanian support treatment and nursing hospitals supported the previously determined key success factor of QMS implementation, i.e. managerial perception of the QMS significance $[1,21]$. Findings of the present research show that managerial perception of the QMS significance correlates with certain QMS organizational ben- efits, such as higher patient satisfaction, more effective communication, safer work environment, better work organization, etc. This relationship might be explained by the fact that the managerial attitude to QM conditions key QMS-related decisions, such as resource allocation and development of QM training systems, which in turn leads to higher levels of QM competence among all level employees.

Managerial satisfaction with the QMS is associated with the level of their QM knowledge as well as their staff training in quality management. Thus QM training of management and staff conditions the success of the QMS implementation in hospitals. In parallel to prior studies, this research also showed that appropriate training is highly significant in the QMS implementation $[21,22]$.

As to the most valued benefits of the QMS (as perceived by hospital managers), these include improved responsi-

Table 7: Factor analysis of the QMS implementation problems

\begin{tabular}{lllc}
\hline Factor & Variable & Loading & Total variance explained \\
\hline $\begin{array}{l}\text { Factor I (QM competence and organizational } \\
\text { resources) }\end{array}$ & Staff training & .432 & $25.24 \%$ \\
& Procedure development, & .833 \\
& Development of work instructions & .709 \\
& Lack of information & .670 \\
Factor II (QM policy) & Lack of financial resources & .642 & .891 \\
& Quality policy definition & .893 & $22.53 \%$ \\
Factor III (QM audit group activities) & Quality goal setting & .679 & $15.13 \%$ \\
& Appointment of local audit group manager & .740 & .432 \\
Factor IV (Employee resistance to QMS & Audit group formation & .854 & $10.35 \%$ \\
implementation) & Use of diagnostic and treatment methods & Employee resistance to QMS implementation &
\end{tabular}


bility and power sharing, better service quality, higher patient satisfaction with services, and improved work organisation. The above research findings are parallel to the results of prior study in health care, which among other benefits comprise patient satisfaction, excellent professional outcomes, no delays, etc. [15].

\section{Limitations}

The paper did not attempt to determine the actual stage of the QMS implementation, assessment of which would have necessitated such means as quality audit, benchmarking, etc. The above issue could serve as a research object for further studies in the area. This paper is built on the managerial perceptions of the QMS implementation, which may bear a certain level of subjectivity.

\section{Conclusion}

Research findings show that as perceived by hospital managers QMS operates in more than a third of Lithuanian support treatment and nursing hospitals. QMS implementation is dependant on the hospital size - currently QMS operates in the majority of large hospitals (over 100 employees), whereas in about half of smaller hospitals QMS is still under implementation.

From the managerial perspective, the most critical issues encountered in the QMS implementation in Lithuanian support treatment and nursing institutions were as follows: procedure development and scarcity of financial resources and information.

Heads of Lithuanian support treatment and nursing hospital consider QMS implementation highly relevant for their hospitals. More than fifty per cent of hospitals have established employee-training systems, and heads of such institutions tend to rate their employee quality management competence (skills and abilities) considerably higher than those from hospitals that do not have respective training systems.

The overall level of managerial satisfaction with the operating QMS is merely mediocre. As to the most valued benefits as perceived by hospital heads these include improved allocation of responsibility and power, service quality, and patient satisfaction with services.

\section{Competing interests}

The author(s) declare that they have no competing interests.

\section{Authors' contributions}

These authors equally contributed to this work.

\section{Additional material}

\section{Additional File 1}

Survey questionnaire items.

Click here for file

[http://www.biomedcentral.com/content/supplementary/1472-

6963-6-120-S1.doc]

\section{References}

I. Striem J, Øvretveit J, Brommls M: Is health care a special challenge to quality management? Insights from the Danderyd hospital case. Q Manage Health Care 2003, I 2:250-258.

2. Seguin C: L'accreditation: une demarche centree sur la qualite des soins. In L'Accreditation des etablissements de sante. De l'experience internationale a l'application francaise Edited by: Christophe Segouin. Paris: Doin Editeurs/Assistance Publique-Hopitaux de Paris; 1998:3-5.

3. Downey-Ennis K, Harrington D: Organizational effectiveness in Irish health-care organizations. Managing Service Quality 2002, I 2:31 6-322.

4. Jackson S: Europe supports UK Government in putting quality at the heart of health care. Health Manpower Management 1998, 24:100-103.

5. Wagner C, Gulácsi, Takacs E, Outinen M: The implementation of quality management systems in hospitals: a comparison between three countries. BMC Health Services Research 2006, 6:50.

6. Lithaunian Standards Board: Lithuanian Standard LST EN ISO 9000:2001. Vilnius 2001.

7. Decree of Lithuanian Health Minister on local medical audit regulations. Valstybès žinios 1998:89-2469.

8. Seimas of the Republic of Lithuania: Decree of Lithuanian Health Minister on the ratification of 2005-2010 health care quality assurance programme dokpaieska.showdoc I?p id=242167\&p query=\&p tr2=].

9. Decree of Lithuanian Health Minister on support treatment and nursing hospitals. Valstybès žinios 2000:18-443.

10. Lithuanian Health Information Centre [http://www.Isic.lt/]

II. Folz DH: Survey for Public Administration Thousand Oaks, Sage; 1996.

12. Øvretveit J: Formulating a health quality improvement strategy for a developing country. International Journal of Health Care Quality Assurance 2004, I 7(7):368-376.

13. Ennis K, Harrington D: Factors to consider in the implementation of quality within Irish healthcare. Managing Service Quality 1999, 9(5):320-326.

14. Yahya S, Goh W: The implementation of an ISO 9000 quality system. International Journal of Quality \& Reliability Management 200I, I 8(9):941-966.

15. Øvretveit J: The Norwegian approach to integrated quality development. Journal of Management in Medicine 2001, I5(2):|25-|4|.

16. Staines A: Benefits of an ISO $900 \mathrm{I}$ certification - the case of a Swiss regional hospital. International Journal of Health Care Quality Assurance 2000, I3(1):27-33.

17. Press I: The measure of quality. Q MANAGE Health Care 2004, I3(4):202-209.

18. van den Heuvel J, Koning L, Bogers AJ, Berg M, van Dijen ME: An ISO $900 \mathrm{I}$ quality management system in a hospital. Bureaucracy or just benefits? International Journal of Health Care Quality Assurance 2005, I 8(5):36I-369.

19. Maxim PS: Quantitative research methods in the social sciences New York, Oxford University Press; 1999.

20. Casadesus M, Karapetrovic S: The erosion of ISO 9000 benefits: a temporal study. International Journal of Quality \& Reliability Management 2005, 22:120-136.

21. Rad AM: A Survey of total quality management in Iran. Barriers to successful implementation in health care organizations. LHS 2005, I 8(3): 12-34.

22. Messner K: Barriers to implementing a quality improvement program. Nursing Management 1998, 29:32-36. 


\section{Pre-publication history}

The pre-publication history for this paper can be accessed here:

http://www.biomedcentral.com/1472-6963/6/120/pre

pub

Publish with Bio Med Central and every scientist can read your work free of charge

"BioMed Central will be the most significant development for disseminating the results of biomedical research in our lifetime. " Sir Paul Nurse, Cancer Research UK

Your research papers will be:

- available free of charge to the entire biomedical community

- peer reviewed and published immediately upon acceptance

- cited in PubMed and archived on PubMed Central

- yours - you keep the copyright
BiolMedcentral 